Supplement of

\title{
Is positive correlation between cloud droplet effective radius and aerosol optical depth over land due to retrieval artifacts or real physical processes?
}

Hailing Jia et al.

Correspondence to: Xiaoyan Ma (xma@nuist.edu.cn)

The copyright of individual parts of the supplement might differ from the CC BY 4.0 License. 


\section{Figure List}

Figure S1. Cloud effective radius (CER) as a function of aerosol optical depth (AOD) over (a) EC, and (b) EU, (c) WE, and aerosol index (AI) over (d) ECO, (e) EUO, and (f) WEO. The dots show the mean CER at each AOD/AI bin of 0.02. The slopes on log-log scale and the least-square fits for $\mathrm{AI}<0.3$ (blue) and $\mathrm{AI}>0.3$ (red), respectively, are provided in panel (d), (e), and (f).

Figure S2. The number of samples for each LWP (x axis) and CF (y axis) bin over (a) EC, (b) EU, (c) WE, (d) ECO, (e) EUO, and (f) WEO.

Figure S3. The number of samples for each LWP bin over (a) EC, (b) EU, (c) WE, (d) ECO, (e) EUO, and (f) WEO. 
Figure S1
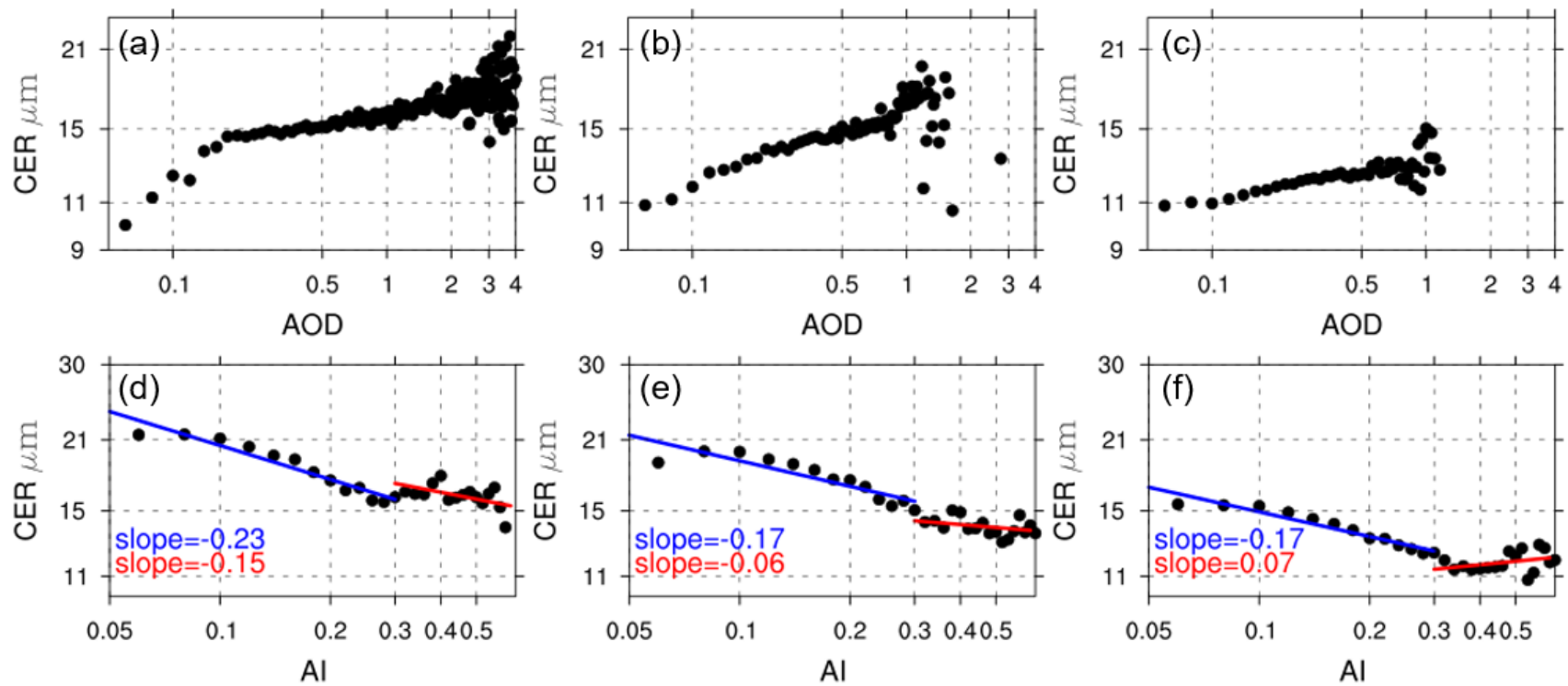

Figure S2
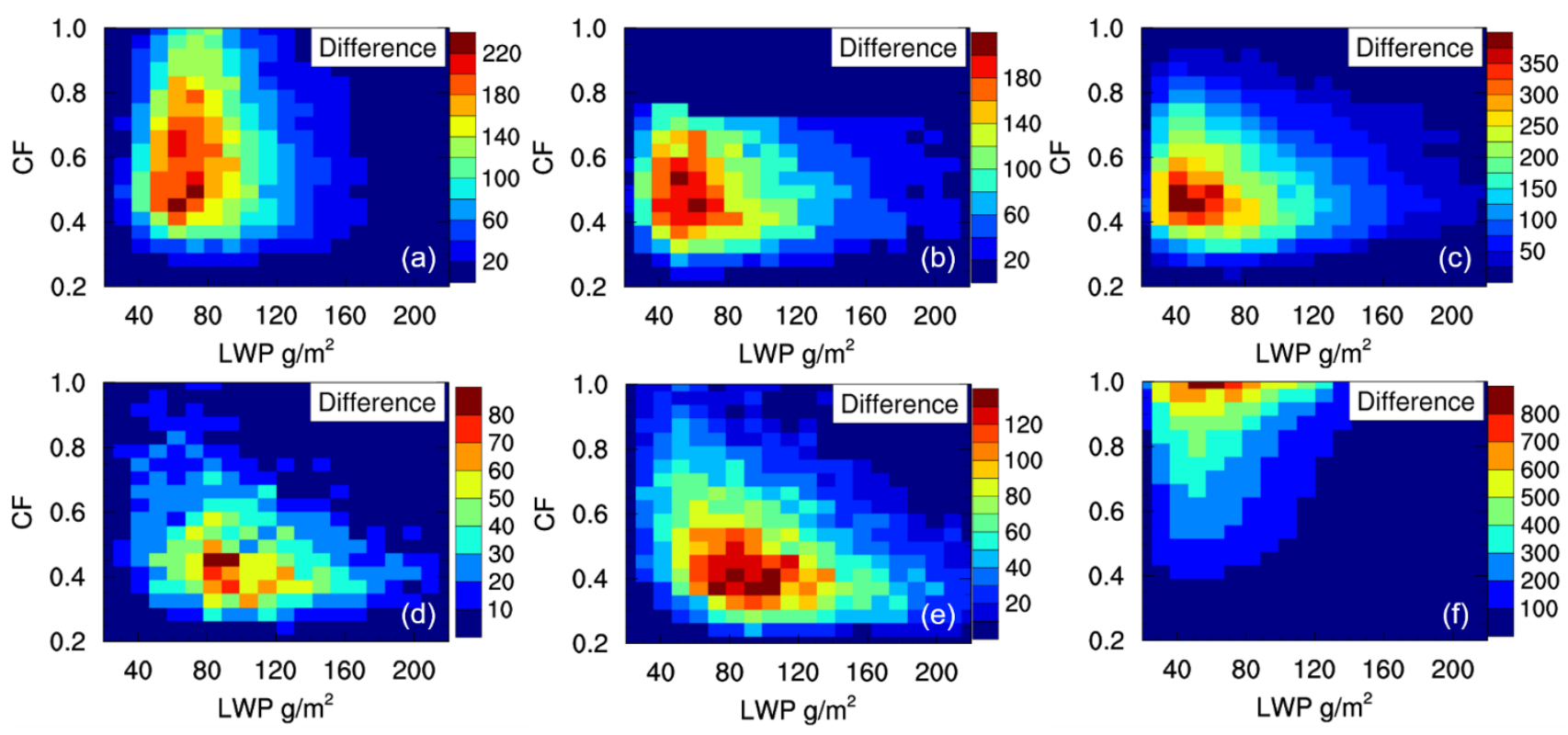
Figure S3

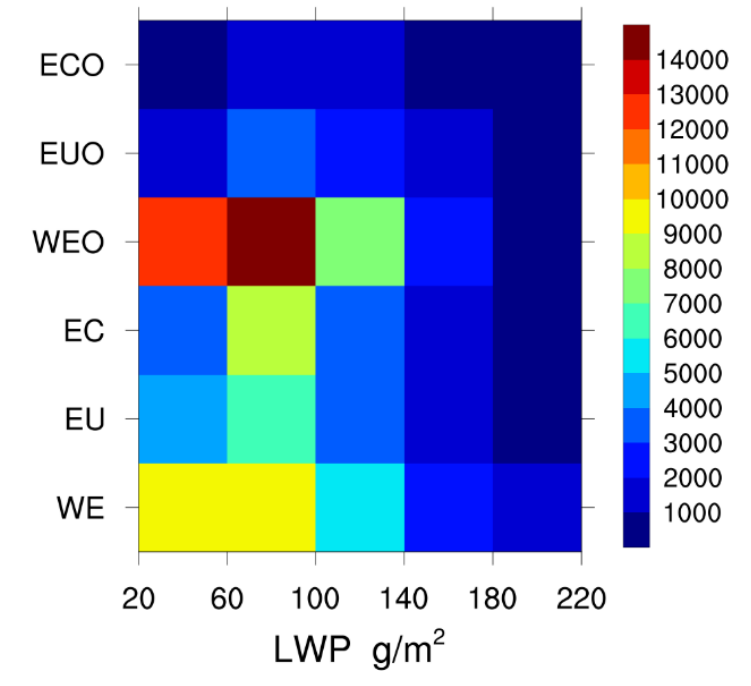

